\title{
A utilização do Google Sala de Aula na Educação Básica: uma plataforma pedagógica de apoio à Educação Contextualizada
}

\author{
Jairo Rodrigo Soares Carneiro ${ }^{1}$, Alba Sandyra Bezerra Lopes $^{1}$, Edmilson \\ Barbalho Campos Neto ${ }^{1}$
}

${ }^{1}$ Instituto Federal de Educação, Ciência e Tecnologia do Rio Grande do Norte (IFRN), Campus Natal - Zona Norte - Brasil

jairo.rodrigo@escolar.ifrn.edu.br, \{alba.lopes, edmilson.campos

\}@ifrn.edu.br

\begin{abstract}
This article aims to present an analysis on the use of the Google Classroom pedagogical tool as a differentiated methodological and entrepreneurial practice of the teaching profession in a contextualized educational environment. The results obtained indicate that the articulation of this AVA in teaching - learning activities in the middle level of teaching, has a strong acceptance by the students as a pedagogical tool to support learning, standing out for the ease in access and the high satisfaction rates demonstrated by the students in developing their activities through Google Classroom - which for many of these, it is the first contact with teaching forms and technologies characteristic of EAD.
\end{abstract}

Resumo. Este artigo tem o objetivo de apresentar uma análise sobre o uso da ferramenta pedagógica Google Sala de Aula, como prática metodológica diferenciada e empreendedora do profissional docente em um ambiente escolar de educação contextualizada. Os resultados obtidos apontam que a articulação desse AVA em atividades de ensino - aprendizagem no nível médio de ensino, tem forte aceitação pelos alunos como ferramenta pedagógica de apoio à aprendizagem, destacando-se pela facilidade no acesso e os altos índices de satisfação demonstrado pelos alunos em desenvolverem suas atividades via Google Sala de Aula - que para muitos destes, trata-se do primeiro contato com formas e tecnologias de ensino característicos da EAD.

\section{Introdução}

Apesar dos avanços tecnológicos e a globalização da internet terem alterado sobremaneira diferentes espaços e segmentos da sociedade quanto à questões políticas, econômicas e culturais, é perceptível que tratando-se de Educação, a maioria dos espaços educacionais - mais especificamente, os espaços das salas de aulas permanecem inalterados (ou seja, lugar em que prevalecem as carteiras e lousas brancas; e tem-se os livros didáticos como as únicas tecnologias presentes). Todavia, há de se concordar que o perfil dos jovens estudantes de hoje, em muito difere-se dos alunos de épocas passadas, haja vista, serem esses, jovens que cresceram ou estão crescendo em contato diário com as novas tecnologias digitais (TAPSCOTT, 1999).

Concordantemente, Kenski (2007), ressalta que apesar de o Brasil não ter ainda atingido os expressos e elevados níveis de uso dos computadores e das redes, tal como ocorrem nos países de primeiro mundo, não significa dizer que a população brasileira 
VII Congresso Brasileiro de Informática na Educação (CBIE 2018)

Anais do XXIV Workshop de Informática na Escola (WIE 2018)

esteja a parte deste processo. Principalmente, tratando-se das gerações mais jovens, que cada vez mais se lançam nas redes para protagonizar suas próprias criações (blogs, wikis, sites, aplicações web etc.), e de igual modo, para constantemente se fazerem presentes em diferentes comunicações e interações via redes, como jogos on-line, redes sociais, salas de bate-papo, mensagens instantâneas etc. Essas constantes formas de interação caracterizam, portanto, as novas mudanças culturais e comportamentais que tipificam esta nova geração - "uma geração digital" (TAPSCOTT, 1999) -, que não falam sobre as novas tecnologias, mas sim sobre o que fazem com elas (KENSKI, 2007).

Logo, caberá que a escola - e corpo docente -, busque cada vez mais articular e integrar as novas tecnologias digitais em práticas educacionais, a fim de melhor atender essa nova geração que prontamente convive e faz uso de diferentes tipos de tecnologias. E não apenas isso, conforme destacado por Moraes (2007), é preciso diversificar os espaços, processo e metodologias educacionais, bem como, utilizar "os recursos tecnológicos que estão disponíveis, [...][colocando-os] a serviço da educação e não mais alijarmos deles" (MORAES, 2007, p. 188).

Assim, os Ambientes Virtuais de Aprendizagem (AVAs), podem ser compreendidos como os novos espaços de mediação para promover a educação (BEHAR, 2009), ao qual integra e articula todos os possíveis cenários outrora apresentados (ou seja, local em que tecnologia e educação convergem). Bem como, considerando a utilização destas plataformas educacionais em atividades de ensinoaprendizagem - em instituições de ensino presenciais - como uma atitude metodológica diferenciada e empreendedora do profissional docente (ao qual busca correlacionar e/ou aproveitar esse potencial dos jovens que convivem constantemente com as tecnologias, com atividades diárias de aprendizagem).

Portanto, este trabalho tem o objetivo de fazer uma análise sobre o uso da ferramenta pedagógica Google Sala de Aula (uma plataforma educacional web de estímulo à colaboração professor/aluno, aluno/aluno), entre alunos e professores dos Cursos Técnicos Integrados Nível Médio, campus Natal - Zona Norte (IFRN), buscando identificar como a ferramenta tem sido explorada, bem como verificar o impacto e a percepção dos alunos com relação a adoção dessa ferramenta educacional em nível institucional.

\section{Trabalhos relacionados}

Embora seja uma ferramenta recente, lançada em 2014 pela Google, alguns trabalhos já abordam o potencial do Google Sala de Aula como ferramenta de apoio à aprendizagem.

No trabalho de Iftakhar (2016), o autor apresenta uma visão geral sobre o Google Sala de Aula - quanto aos recursos e benefícios da utilização desta plataforma -, e busca principalmente, responder às seguintes questões: Quais fatores influenciam o professor a usar o Google Sala de Aula? Como o professor usa Google Sala de Aula em seu ensino? Quais são as barreiras para usar o Google Sala de Aula? E por fim, quais são as respostas dos alunos ao Google Sala de aula? Ao final do estudo, Iftakhar (2016) destaca que entre as principais considerações apresentadas pelos professores participantes da pesquisa quanto às questões levantadas sobre a plataforma Google Sala de Aula, estão a de que o mesmo: é potencialmente útil para auxiliar o professor no 
VII Congresso Brasileiro de Informática na Educação (CBIE 2018)

Anais do XXIV Workshop de Informática na Escola (WIE 2018)

cumprimento do cronograma da disciplina; o ambiente "Classroom" permite aperfeiçoar o processo de interação e colaboração professor/aluno, aluno/aluno; facilita o acesso do aluno à materiais de aula; e ainda pode ser usada por motivação organizacional e de desenvolvimento pessoal (do professor).

Os autores Affonso SOUZA (2016) e Flávia SOUZA (2016) descrevem em seu trabalho, a experiência vivida mediante a utilização do Google Classroom em uma turma do ensino médio, como plataforma educacional de apoio às atividades de ensinoaprendizagem na disciplina de matemática. Ao final do trabalho, os autores constataram que a inclusão da plataforma digital "Classroom" em atividades de aprendizagem no ensino médio, tende a despertar o interesse dos alunos, bem como propiciar trabalhos que promovam maior interação e colaboração entre estes, dentro das salas de aula, contribuindo assim para o processo de ensino e aprendizagem, sendo estes os principais pontos positivos aos quais relacionaram a utilização do ambiente "Classroom".

Os autores Rocha et al., (2017) relata em seu trabalho uma experiência de utilização do ambiente virtual Sócrates - no apoio a disciplina de Geografia -, indicando que propicia o desenvolvimento de atividades pedagógicas baseadas em modelos colaborativos, e tornam a prática docente mais dinâmica e cooperativa. E ainda, é destacado pelos autores, que o AVA além de servir como complemento às aulas, propicia "uma melhoria no processo de ensino e aprendizagem e inovação na prática pedagógica para a disciplina de Geografia" (ROCHA, et al., 2017).

\section{AVA como Atitude Empreendedora e Diferenciada do Docente da Instituição}

Desde 1996, no Brasil, conforme destacado na LDB 9.394/96, compreende ao ensino médio, a etapa final da educação básica - com duração mínima de três anos -, que objetiva entre outras coisas, a consolidação e o aprofundamento dos conhecimentos adquiridos no ensino fundamental, bem como a formação do cidadão para a vida social e para o mercado de trabalho. De forma que ofereça o conhecimento necessário para que o estudante possa dar continuidade a sua formação acadêmica.

No âmbito escolar, o ensino presencial tradicional apesar de predominante nas relações de ensino, está cada vez mais dividindo espaços com modelos crescentes e inovadores de Educação a Distância (EAD) (BEHAR, 2009). A EAD hoje, em muito se difere dos modelos de ensino tradicionais e estáticos aos quais conhecemos, sendo portador de identidade e características próprias, não sendo poucas as instituições de ensino nos diferentes níveis que de alguma forma fazem uso dela (ROSINI, 2010). E no Brasil, não é diferente. Segundo Marcusso (2009), apesar de o ensino médio tradicional ser presencial, tem sido utilizado de maneira cada vez mais intensa, ferramentas e tecnologias (típicas da EaD) aplicada à educação.

Um dos principais exemplos concretos da inserção de elementos típicos da $\mathrm{EaD}$ nos espaços educacionais tradicionais, está na utilização das plataformas digitais de aprendizagem. Plataformas estas, que correspondem ao principal canal e meio pedagógico tipicamente característico da Educação a Distância (EAD). No entanto, mesmo nesse contexto inovador em que diferentes espaços (presencial e virtual) e as tecnologias digitais têm convergido, é perceptível que alguns professores ainda demonstram forte resistência quanto à prática com os ambientes virtuais de aprendizagem (AVA) em atividades de ensino. Por outro lado, diferentemente destes, temos aqueles têm vontade de conhecer e trabalhar com AVAs, que compreendem seu 
VII Congresso Brasileiro de Informática na Educação (CBIE 2018)

Anais do XXIV Workshop de Informática na Escola (WIE 2018)

valor pedagógico e potencial para interações, que podem em última instância resultar em aprendizagem.

Considerando, portanto, a utilização destas plataformas educacionais em atividades de ensino-aprendizagem como uma atitude empreendedora do profissional docente - haja vista, existirem inúmeras barreiras para integração destes ambientes nos espaços escolares, que vão desde a infraestrutura escolar (acesso à computador e internet), quanto à formação docente (para o uso das TDICs) -, temos que estes, além de compreenderem os valores e potenciais pedagógicos dos ambientes virtuais para desenvolverem atividades de ensino-aprendizagem, estão assim, significativamente correlacionando e/ou aproveitando esse potencial dos jovens que convivem constantemente com as tecnologias, com as atividades diárias de ensino-aprendizagem. Assim, trata-se de uma atitude empreendedora e diferenciada do profissional docente, que pode assim:

“[...] aproveitar o interesse natural dos jovens estudantes pelas tecnologias e utilizá-las para transformar a sala de aula em espaço de aprendizagem ativa e de reflexão coletiva; capacitar os alunos não apenas para lidar com as novas exigências do mundo do trabalho, mas, principalmente, para a produção e manipulação das informações e para o posicionamento crítico diante dessa nova realidade" (Kenski, 2007, p. 103).

No entanto, tratando-se de Educação, não apenas o professor, mas também a escola certamente desempenha um forte papel nesse processo, com base na escolha - e uso - das tecnologias que farão a mediação entre professores, alunos e os conteúdos.

Nesse mesmo contexto, Tardif (2014), compreende a escola como sendo um "[...] lugar organizado, especial e socialmente separado dos outros espaços da vida social e cotidiana" (TARDIF, 2014, p. 55). Todavia, esta separação, trata-se de uma compreensão espacial - da escola convencional -, ou seja, lugar para a atuação regente do profissional docente. Pois, como bem destacado por Cunha (2012, p. 22) "a escola é uma instituição contextualizada, isto é, sua realidade, seus valores, sua configuração variam segundo as condições histórico-sociais que a envolvem”.

Compreendendo, portanto, a escola, como uma instituição contextualizada, temos que a mesma, deverá estar entre outras coisas, articulada e integrada ao atual contexto tecnológico em que vivemos. Sendo assim, caberá a escola fundamentalmente dispor aos agentes educacionais (professor/aluno), o acesso, bem como o devido suporte às novas tecnologias educacionais, a fim de dinamizar as práticas e atividades corriqueiras tradicionais de ensino e aprendizagem.

\section{Google Sala de Aula como uma nova ferramenta de apoio pedagógico}

Existe hoje uma variada gama de excelentes plataformas educacionais desenvolvidas para web e dispositivos móveis (como por exemplo, o Teleduc, Moodle, Aulanet, etc.) que ajudam no trabalho diário dos professores, de modo que, estes podem gerenciar de forma eficiente suas respectivas salas de aula e, em última instância, melhorar o ensino.

Destacando-se como um dos principais lançamentos do pacote de ferramentas de produtividades ao qual compõe o App do G Suite for Education, o "Google Classroom", ou Google Sala de Aula, como é conhecido no Brasil, foi lançado oficialmente ao público em 10 de setembro de 2014 pela Google. E, embora a sua pouca "idade" frente 
VII Congresso Brasileiro de Informática na Educação (CBIE 2018)

Anais do XXIV Workshop de Informática na Escola (WIE 2018)

outras soluções - como, por exemplo, o ambiente Moodle -, o Google Sala de Aula destaca-se como uma das principais plataformas educacionais hoje existentes.

O Google Sala de Aula é uma plataforma educacional web de incentivo à colaboração - professor/aluno, aluno/aluno -, cuja distribuição é gratuita para escolas e instituições de ensino que usam o Google Apps for Education. Seu objetivo é oferecer um espaço digital de apoio às práticas pedagógicas desenvolvidas diariamente entre professores e alunos - dentro e fora das salas de aula -, além de estimular um aprendizado divertido e colaborativo com o uso dos recursos digitais.

\subsection{Conhecendo o Google Sala de Aula}

O ambiente Google Sala de Aula tem dois tipos de usuários: o professor, que é responsável pela criação, organização e gerenciamento das turmas virtuais; e os alunos, que acessam os recursos do AVA para consultar os materiais de apoio e realizar as atividades. Ambos os usuários - professor e alunos - precisam se identificar (login e senha) sempre que quiserem acessar a sala de aula virtual. As salas virtuais criadas pelo professor possuem um código que deve ser repassado aos alunos. De posse do código, os alunos ingressam no ambiente e tem acesso à sala criada pelo professor.

O ambiente "Classroom" apresenta três fluxos principais, são eles:

Mural - onde são alocadas as atividades que os professores deixam para os estudantes. Estas ficam dispostas em ordem cronológica de postagem (da mais recente para a mais antiga). Nessa Guia, o professor além de elaborar e criar atividades (datadas com prazo de entrega ou simplesmente agendadas para publicação futura) pode anexar diferentes tipos e formatos de materiais de apoio (arquivos textos, links, vídeos, áudios, formulários etc.). Assim, estes materiais podem facilmente ser acessados, visualizados ou baixados, convenientemente, pelo aluno a qualquer hora e em qualquer lugar.

Guia Alunos - onde é possível identificar quem são os alunos da turma; enviar mensagens personalizadas para os alunos - ou mensagens aluno/aluno -, além de convidar outros estudantes para participarem da turma.

Guia Sobre - é espaço que possibilita ao professor disponibilizar materiais de apoio (textos, ementas, cronogramas, materiais de orientação etc.), bem como descrições sobre a disciplina. Nesta aba existe ainda um campo que possibilita ao professor convidar outros colegas para trabalharem de forma colaborativa em uma mesma turma - possibilitando a estes desenvolverem atividades interdisciplinares.

Além disso, professores e alunos podem usar campos específicos da plataforma (e-mail, barra de comentário, etc.) para se comunicar e interagir pedagogicamente - de forma síncrona e assíncrona - em atividades de ensino.

\section{Possibilidades Pedagógicas com o uso do Google Sala de Aula}

São diversas as possibilidades pedagógicas para o trabalho docente - e seus respectivos alunos - propiciados pelo ambiente virtual Google Sala de Aula. De modo que neste trabalho, buscamos correlacioná-los aos conteúdos teóricos estudados.

Extensão do tempo das aulas: Acreditamos, assim como Tardif (2014), na evidência de que "[...] o tempo escolar não acompanha diretamente o tempo da aprendizagem dos alunos. [Haja vista que,] o aprendizado requer um tempo variável segundo os indivíduos e os grupos" (TARDIF, 2014, p. 76). Neste contexto, o ambiente 
VII Congresso Brasileiro de Informática na Educação (CBIE 2018)

Anais do XXIV Workshop de Informática na Escola (WIE 2018)

Google Sala de Aula pode claramente ser utilizado como extensão do tempo das aulas, de modo que professores e alunos podem não apenas se contatarem de forma síncrona/assíncrona fora dos espaços - e tempo - das salas de aula, mas também, continuar desenvolvendo fora do tempo das salas de aula, atividades de ensino e aprendizagem. Ou seja, a plataforma educacional "Classroom", apresenta-se "como um contexto de aprendizagem diferenciado do contexto tradicional, no qual temos um espaço físico estabelecido e um tempo estipulado que determinam as interações e caracterizam uma sala de aula" (BEHAR E WAQUIL, 2009, p. 147).

Ampliação das atividades propostas no Ensino Médio: De acordo com Romiszowsky (2002), espera-se que um aluno de ensino médio realize duas ou três horas de estudo extra por dia. Portanto, no total (análise em nível 'macro'), um currículo de uma escola secundária convencional é, aproximadamente, dois terços 'presencial' e um terço 'não-presencial' (apud, TORI, 2009, p. 121). Este resultado, portanto, aponta que mesmo em cursos presenciais, invariavelmente, serão previstas e/ou realizadas pelos alunos atividades a distância (TORI, 2009). Semelhantemente, Kenski (2007), compreende o processo educacional, como sendo, "predominantemente uma relação semipresencial. Impossível pensar que todas as atividades educativas previstas ocorram exclusivamente no espaço da escola, na sala de aula, diante de um professor" (KENSKI, 2007, p. 86). Portanto, o professor, desejoso em possibilitar aos alunos, um novo espaço pedagógico que consequentemente, possibilite aos alunos a ampliação das atividades escolares, pode claramente se beneficiar com a utilização do Google Sala de Aula. Haja vista que esta plataforma pertence a um conjunto maior de uma poderosa aplicação tecnológica que integra Documentos Google, Formulários, Google Drive, calendário etc., que podem ser exploradas pelo professor, para desenvolver com os alunos diferentes tipos de atividades pedagógicas - individuais ou grupais.

Melhoria da interação: Para Behar, Bercht e Longhi (2009, p. 204), "Educação não existe sem interação". Neste contexto, a utilização do Google Sala de Aula em instituições de ensino presenciais - nos quais já conta com a vantagem da presença física dos seus integrantes (TORI, 2009) -, só vem a acrescentar para a melhoria do processo de interação/comunicação professor/aluno, aluno/aluno. Pois o "Classroom" possibilita a estes interação via postagens de materiais, comentários e dúvidas; envio de atividades com prazos definidos ou não; possibilita ao professor fornecer feedback aos alunos referente à atividades entregues; além de oferecer aos alunos e professores uma caixa de e-mail acadêmico específico para as atividades escolares.

Estímulo à Pesquisa: Para Waquil e Behar (2009), o acesso, consulta e a utilização dos materiais e conteúdos de curso disponíveis no ambiente virtual pelo aluno é uma característica de pesquisa em AVAs. Sendo benéfico ao aluno, não apenas pelo armazenamento e acesso dos materiais de estudo que são dispostos no AVA, mas, sobretudo, por dispor de muitos dos registros do que ocorre na sala de aula (postagens dos alunos, intervenções do professor etc.), que para estes autores, trata-se de uma das principais vantagens "[...] do AVA em relação ao ambiente presencial, em que muito do que ocorre em aula não fica registrado" (WAQUIL E BEHAR, 2009, p. 159). Neste contexto, o Google Sala de Aula é potencialmente útil e diferenciado, haja vista que, além de o professor poder compartilhar materiais didáticos e de estudo com seus alunos para uso em sala de aula, temos que mesmo fora das salas de aulas, estes materiais podem facilmente ser acessados, visualizados ou baixados, convenientemente, pelo aluno em qualquer hora e lugar. Possibilitando ao aluno dar continuidade a seus estudos. 
VII Congresso Brasileiro de Informática na Educação (CBIE 2018)

Anais do XXIV Workshop de Informática na Escola (WIE 2018)

\section{Resultados e Discussões}

Esta seção apresenta o resultado da pesquisa realizada para analisar o uso da ferramenta pedagógica Google Sala de Aula entre alunos e professores dos Cursos Técnicos Integrados Nível Médio, campus Natal - Zona Norte (IFRN). Cujo objetivo foi identificar como a ferramenta tem sido explorada e verificar o impacto e a percepção dos alunos com relação à adoção de uma ferramenta educacional web em nível institucional. Essa plataforma educacional foi adotada pela instituição por ser uma ferramenta gratuita oferecida pela Google através do pacote Google For Education ${ }^{1}$ a instituições de ensino. $\mathrm{O}$ acesso dos estudantes ao pacote educacional é feito através do mesmo usuário e senha que utilizam para acessar o sistema acadêmico da instituição. No primeiro acesso à plataforma, via sistema acadêmico, os usuários escolhem uma dentre algumas opções de e-mail acadêmico e, a partir de então, passam a ter acesso às funcionalidades do Google For Education. $\mathrm{O}$ acesso à plataforma é feito sempre através da autenticação via sistema acadêmico institucional.

Neste trabalho, foi feita a pesquisa com os alunos considerando uma amostra dos estudantes do nível médio matriculados na instituição. Para tanto, optou-se por aplicar questionários somente aos alunos do turno vespertino, tendo sido o número de respondentes ao questionário um total de 92 alunos, que corresponde a 32,9\% do número de alunos do nível médio vespertinos atualmente matriculados na instituição.

\subsection{Perfil dos participantes da pesquisa}

Inicialmente, foi procurado identificar o perfil dos alunos participantes da pesquisa. Verifica-se que a maioria dos alunos, estão entre as faixas etárias de 15 e 16 anos, o que corresponde a 50\%, seguidos dos que têm entre 17 e 18 anos (45\%) ou mais (5\%). Quanto aos locais em que informam ter mais acesso à computador e internet, apenas duas entre as demais opções (Casa de amigos/parentes, Lan House) foram assinaladas. Os alunos responderam em sua maioria acessam de casa (68\%), seguido da escola (22\%), ao qual identificamos como um fator positivo para o uso e adequação das atividades escolares com o AVA.

Também foi buscado investigar como se dá a participação desses alunos nas plataformas de comunicação/redes sociais atuais, com relação ao acesso e à publicação. Verificou-se que entre as opções dadas (Youtube, Twitter, Instagram, Facebook, respectivamente), numa escala de frequência (entre Diariamente à Nunca), os espaços webs (Instagram e Facebook), são significativamente mais utilizados pelos alunos em atividades de postagem/comentários. Por fim, buscamos identificar com que frequência os alunos usam plataformas de jogos/redes sociais (Facebook, whatsapp, etc.), para interagir e se comunicar. Quanto a isso, constatou-se haver um uso massivo e diário pelos alunos, principalmente, tratando-se das redes sociais (89\%). Outros $11 \%$ informam interagir (ou não) em menor grau nesses ambientes.

Posteriormente, trazendo para um contexto educacional, foi buscado identificar entre os alunos, possíveis experiências com EAD e AVAs que não o Google Sala de Aula. Verifica-se com base na Figura 1.a, que aproximadamente de $69 \%$ dos alunos não possuem experiências formais com ensino a distância (EAD), em detrimento dos demais (21\%). Verifica-se também com base na Figura 1.b, que cerca de $87 \%$ dos alunos, não

\footnotetext{
${ }^{1}$ https://edu.google.com
} 
VII Congresso Brasileiro de Informática na Educação (CBIE 2018)

Anais do XXIV Workshop de Informática na Escola (WIE 2018)

possuem experiências relacionados a uso de outros AVAs (Moodle, Edmodo, Teleduc, etc.). Outros $13 \%$ informaram possuir alguma experiências com AVAs.

(a)

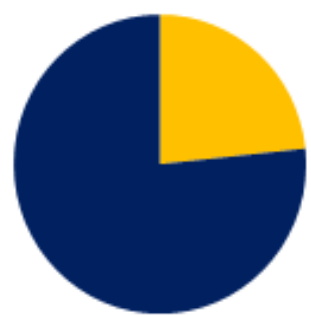

I $\operatorname{Sim}(21 \%)$

— Não (69\%)

(b)

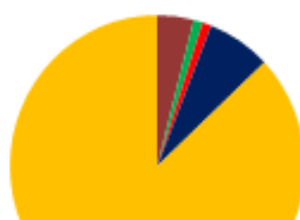

Moodle (4\%)

n Edmodo (1\%)

- Teleduc (1\%)

- Outros (7\%)

Não possui experiência comAVAs (87\%)

Figura 2: Resultados: (a) Experiências em EAD; (b) Experiências com AVAs.

A análise destes resultados nos permite inferir que a utilização do Google Sala de Aula na instituição, está contribuindo não apenas para dinamizar as atividades de aprendizagem, mas também para a introdução e familiarização dos estudantes com plataformas e formas de ensino característicos da EAD.

\subsection{Sobre o Google Sala de Aula}

Complementarmente, foi buscado identificar com que frequência o AVA é acessado pelos alunos, e quais os níveis de satisfação que estes demonstram acerca desta plataforma. Verifica-se com base na Figura 2.a, que cerca de $64 \%$ dos alunos costumam acessar o ambiente diariamente ou pelo menos algumas vezes na semana, em detrimento dos demais (36\%), que informa não acessar frequentemente a ferramenta. Este resultado nos possibilita inferir que o AVA tem favorecido aos alunos não apenas no acesso aos conteúdos de curso e atividades de classe, mas, sobretudo, para que estes mesmo fora do ambiente escolar possam dar continuidade às atividades de aprendizagem. Além disso, verifica-se com base na Figura 2.b, que os alunos estão em sua maioria satisfeitos/a muito satisfeitos (81\%), em acessar e desenvolver suas atividades na plataforma. Outros $19 \%$ apresentam menor grau de satisfação. É importante ressaltar que não constam entre os respondentes, alunos insatisfeitos quanto à utilização do Google Sala de Aula.

(a)

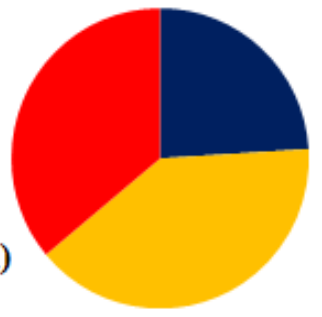

- Diariamente $(24 \%)$

Algumas vezes na

semana $(40 \%)$

- Algumas vezes no mês $(36 \%)$

Nunca (0\%)

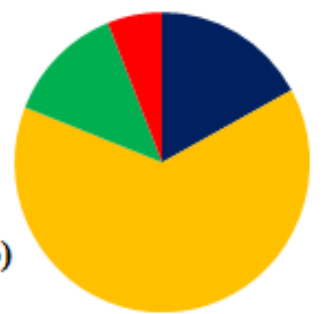

- Muito satisfeito (17\%)

Watisfeito $(64 \%)$

- Indiferente (13\%)

- Pouco satisfeito $(6 \%)$

Insatisfeito (0\%)

Figura 2: Resultados: (a) Acesso a ferramenta; (b) Níveis de Satisfação.

A pesquisa buscou ainda identificar possíveis dificuldades entre os alunos, quanto à utilização do ambiente Google Sala de Aula, e ainda se estes possuem o aplicativo do "Classroom", instalado em seus dispositivos móveis. Os resultados apontam que $68 \%$ dos alunos não apresentam dificuldades na utilização da plataforma. Outros $29 \%$ informam ter um pequeno grau de dificuldade, enquanto que cerca de $3 \%$ alegam maior grau de dificuldade. E, tratando-se de possuírem ou não o aplicativo "Classroom" instalado em seus dispositivos móveis, verifica-se que cerca de $31 \%$ dos alunos tem o aplicativo instalado, em detrimento dos demais (69\%).

É válido ressaltar, que a integração do ambiente Google Sala de Aula aos aparelhos móveis dos alunos a partir do aplicativo é benéfico, na medida em que ao ter o aplicativo instalado, os alunos podem de imediato receber notificações acerca de 
VII Congresso Brasileiro de Informática na Educação (CBIE 2018)

Anais do XXIV Workshop de Informática na Escola (WIE 2018)

novas atividades, materiais, prazos de entrega, etc. Que possibilita ao aluno um maior controle e acompanhamento das atividades de aprendizagem. Tratando-se do número de disciplinas que no atual semestre (2018.1) contam com uma sala virtual do Google para apoio ao professor, constatou-se que entre três e quatro disciplinas curriculares - de uma média de nove disciplinas semestrais -, foram criadas no ambiente Google Sala de Aula.

\section{Conclusão}

Esse trabalho apresentou resultados de uma pesquisa realizada com alunos dos Cursos Técnicos Integrados do Nível Médio, campus Natal - Zona Norte (IFRN), utilizando uma abordagem metodológica de pesquisa quantitativa. Constatou-se inicialmente - tal como, fundamentado neste trabalho (KENSKI (2007), TAPSCOTT, 1999), a existência de um perfil ativo dos alunos em ambientes webs (youtube, Instagram, facebook, etc.) aos quais tipificam esta nova geração de estudantes. E assim sendo, compreendemos que "não há [mais] como ignorar as novas linguagens, cultura e hábitos dos jovens, para os quais a separação entre o virtual e real é cada vez mais tênue" (TORI, 2009, P. 121). De modo que este potencial e convívio dos jovens com as tecnologias devem ser explorados e convergidos em novas possibilidades de aprendizagem.

Tratando-se entre outras coisas, acerca do uso, satisfação, benefícios e possibilidades pedagógicas do Google Sala de Aula, constatou-se que a articulação do Google Sala de Aula em atividades de ensino-aprendizagem no nível médio de ensino, tem forte aceitação pelos alunos como ferramenta pedagógica de apoio à aprendizagem. O que por certo modo já era esperado, não apenas em decorrência as características intrínsecas ao AVA, ou seja, design e interface humano-computador amigável e de fácil usabilidade - típico das tecnologias Google -, mas sim porque afinal eles vivem constantemente em ambientes saturados de meios digitais.

Por fim, consideramos que os elevados índices de satisfação apresentados pelos alunos quanto à plataforma, assim como, mediante o baixo grau de dificuldades apresentados pela maioria dos alunos quanto à utilização deste ambiente, além de contribuir para indicação de que o Google Sala de Aula pode significativamente auxiliar as atividades de ensino em uma modalidade presencial, e para a inicialização de atividades com AVAs em instituições de ensino de educação básica (nível médio) - haja vista que, conforme apresentado pela maioria dos alunos, o uso do Google Sala de Aula, trata-se do primeiro contato com formas e tecnologias de ensino característicos da EAD. Pode também, contribuir com a comunidade escolar, principalmente para os docentes que ainda não conhecem o ambiente Google Sala de Aula.

\section{Referências}

AJUDA DO SALA DE AULA. Sobre o Google Sala de Aula. Disponível em: $<$ https://support.google.com/edu/classroom/answer/6020279?hl=ptBR\&ref_topic=7175444>. Acesso em: 07 jun. 2018.

BEHAR, P. A. Modelos pedagógicos em educação a distância. In: Modelos pedagógicos em educação a distância. Porto Alegre: Artmed, 2009. P. 15 - 32.

BEHAR, P. A; WAQUIL, M. P. Princípios da pesquisa científica para investigar ambientes virtuais de aprendizagem sob o ponto de vista do pensamento complexo. In: BEHAR, P. A. (org). Modelos pedagógicos em educação a distância. Porto Alegre: Artmed, 2009. P. 146 - 178. 
VII Congresso Brasileiro de Informática na Educação (CBIE 2018)

Anais do XXIV Workshop de Informática na Escola (WIE 2018)

BEHAR, P. A; NOTARE, M. R. A comunicação matemática on-line por meio do ROODA Exata. In: BEHAR, P. A. (org). Modelos pedagógicos em educação a distância. Porto Alegre: Artmed, 2009. P. 179 - 203.

BEHAR, P. A; BERCHT, M; LONGHI, M. T. A busca pela dimensão afetiva em ambientes virtuais de aprendizagem. In: BEHAR, P. A. (org). Modelos pedagógicos em educação a distância. Porto Alegre: Artmed, 2009. P. 204 - 231.

CUNHA, Maria Isabel da. O bom professor e sua prática. 24. ed. Campinas, SP: Papirus, 2012. 159 p. (Magistério: formação e trabalho pedagógico).

IFTAKHAR, S. GOOGLE CLASSROOM: WHAT WORKS AND HOW? Disponível em: <http://jesoc.com/wp-content/uploads/2016/03/KC3_35.pdf>. Acesso em: 05 jun. 2018.

KENSKI, Vani Moreira. Educação e tecnologias: o novo ritmo da informação. 2. ed. Campinas, SP: Papirus, 2007. 141 p. il. (Papirus educação).

TAPSCOTT, D. Educating the Net Generation. Disponível em: $<$ http://learnwith.tech/ed300/resources/Educating_Net_Generation.pdf $>$. Acesso em: 10 jun. 2018

MARCUSSO, N. T. EAD e tecnologia no ensino médio. In: LITTO, Fredric M. ; FORMIGA , Marcos (orgs). Educação a distância: o estado da arte. São Paulo: Pearson Education, 2009. p. 182 - 187.

MINISTÉRIO DA EDUCAÇÃO. Lei de Diretrizes e Bases da Educação Nacional. Lei $\mathrm{n}^{\circ} \quad 9.394 . \quad 1996 . \quad$ Disponível em: <http://www.planalto.gov.br/ccivil_03/Leis/L9394.htm>. Acesso em: 07 jun. 2018.

MORAES, Maria Cândida. O paradigma educacional emergente. 13. ed. São Paulo: Papirus, 2007. 239 p. (Práxis).

ROCHA, J. I. G. et al. A Utilização do Ambiente Virtual de Aprendizagem Sócrates na Educação Básica: Um caminho de Reconstrução da Prática Pedagógica. Disponível em: <http://www.br-ie.org/pub/index.php/wie/article/view/7269/5067>. Acesso em: 05 jun. 2018.

ROSINI, Alessandro Marco. As novas tecnologias da informação e a educação a distância. São Paulo: Cengage Learning, 2010. 131 p. il.

SOUZA, A.; SOUZA, F. Uso da Plataforma Google Classroom como ferramenta de apoio ao processo de ensino e aprendizagem: Relato de aplicação no ensino médio. Disponível em:<http://rei.biblioteca.ufpb.br/jspui/bitstream/123456789/3315/1/ACSS30112016. pdf $>$. Acesso em: 10 jun. 2018.

TARDIF, Maurice. O trabalho docente: elementos para uma teoria da docência como profissão de interações humanas. 9. ed. Petrópolis: Vozes, 2014. 317 p. il.

TORI, R. Cursos híbridos ou blended learning. In: LITTO, Fredric M.; FORMIGA, Marcos (orgs). Educação a distância: o estado da arte. São Paulo: Pearson Education, 2009. P. $121-128$. 